In: SILVEIRA, Paula Lemos (Org.). O ensino em contexto pandêmico [livro eletrônico]. São Paulo: Vecher, 2021. Disponível em: <https://doi.org/10.47585/9786599324239>.

\title{
Nos vemos na tela! A experiência de ensinar Libras para ouvintes a partir das Metodologias Ativas
}

\author{
Vanessa da Silva Vargas $^{1}$ e Camila G. dos Santos do Canto ${ }^{2}$ \\ doi.org/10.47585/9786599324239.6
}

Este texto busca apresentar uma experiência de ensino dentro do contexto pandêmico. A experiência mencionada ocorre em dois âmbitos concomitantemente: o ensino de Libras para ouvintes, em escola pública e o desenvolvimento de um projeto de Mestrado, em universidade também pública. Além do relato acerca das vivências docentes e discentes durante o período, trazemos também temas que consideramos relevantes tanto para nossa nova prática docente, quanto para a nossa pesquisa de mestrado. Dentro das peculiaridades apresentadas pelo momento social, trazemos à discussão o uso das TDIC, as Metodologias Ativas, com destaque para Sala de Aula Invertida e a mudança comportamental da geração Z, com maiores possibilidades de autonomia na aprendizagem.

Palavras-chave: Memória institucional; Preservação cultural; Instituto Federal do Rio de Janeiro.

1 Mestranda em Ensino de Línguas, Universidade Federal do Pampa. http://lattes.cnpq.br/3331624951051362. E-mail: vanessavargas.aluno@unipampa.edu.br.

2 Doutora em Linguística Aplicada, Univesidade Católica de Pelotas. http://lattes.cnpq.br/7637826244661176.

E-mail: camilagds@gmail.com 


\section{Introdução}

O mundo contemporâneo vem passando por rápidas e profundas transformações sociais e tecnológicas. Ao fim de 2019 e início de 2020, fomos surpreendidos por um vírus até então desconhecido que viria mudar completamente nossas vidas. As TDIC (Tecnologias Digitais de Informação e Comunicação) que já ocupavam um lugar de destaque em nosso cotidiano pessoal, passaram a fazer parte também do nosso trabalho, sobretudo na área educacional. Em tempos pandêmicos, cada um em sua casa, toda nossa vida precisou ser reinventada e a educação não ficou de fora. Com escolas fechadas, poucos recursos e um enorme desafio: ensinar de forma remota.

Não bastassem as adversidades gerais enfrentadas por todos, nos vimos desafiados a encarar aulas de mestrado, ministrado de forma remota para a elaboração de um projeto que visava ensinar Libras (Língua Brasileira de Sinais) uma língua de modalidade visoespacial através de uma tela. A mesma tela que antes era ocupada por intérpretes, fazendo a acessibilidade dos surdos, passou também a ser usada para ensinar Libras para ouvintes, observando todas as peculiaridades deste ensino.

Para facilitar o processo de ensino-aprendizagem dos alunos que ficaram do outro lado da tela, pude contar com o aporte do mestrado, que viabilizou muitas leituras e trocas com colegas e docentes sobre as Metodologias Ativas. Todas elas voltadas ao fomento de um ensino ativo que prioriza o protagonismo dos alunos. Nosso foco ficou especificamente no uso da Sala de Aula Invertida - SAI - que visa inverter o processo de aprendizagem, a partir da utilização de recursos atuais como o áudio, vídeo e Internet (BERGMANN; SAMS, 2016), favorecendo o engajamento do estudante no processo de construção do saber.

Este relato traz não só a nossa experiência como docentes durante a implementação do ensino remoto nas redes públicas e/ou privadas, mas também um recorte de uma pesquisa-ação ligada ao Mestrado Profissional em Ensino de Línguas da Unipampa Bagé .

Conforme relatado anteriormente, foi através do mestrado e da orientação da Profa. Dra. Camila Gonçalves dos Santos do Canto que o uso das Metodologias Ativas se fez possível. Nossa proposta já era trabalhar através da Sala de Aula Invertida, para que o tempo em sala de aula fosse melhor aproveitado, visando a pouca carga horária da disciplina e Libras. A Metodologia da Sala de Aula Invertida prevê práticas e trocas durante o período da aula presencial/síncrona, dando maior ênfase na autonomia dos alunos para que eles pudessem se a apropriar mais dos conhecimentos da Libras, considerada uma L2 de modalidade distinta da L1 de ouvintes, por usar o campo visual.

Como forma de mediação da aprendizagem utilizamos as TDIC disponíveis aos alunos. Em linhas gerais, buscamos ferramentas de vídeo que pudessem ser usadas em aulas síncronas como Google Meet e assíncronas, como gravadores e editores de vídeos disponíveis nos smartphones dos deles.

Também já mencionado anteriormente, objetivamos dar autonomia aos alunos e verificar através do olhar crítico deles mesmos a potencialidade dessas aulas. Para o desenvolvimento da pesquisa que culmina nesse relato, dividimos a atividade em duas etapas: a primeira, serviu de diagnóstico, uma pesquisa 
realizada através do Google Formulários, com o objetivo de conhecer quais ferramentas digitais e tipo de acesso à internet os alunos tinham disponíveis além de conhecimentos prévios já adquiridos sobre a Libras - vale ressaltar que os participantes desta pesquisa já eram alunos de Libras e, portanto, já tinham alguns conhecimentos adquiridos. Logo em seguida, a segunda etapa consistiu na elaboração de uma sequência didática digital e assíncrona com a oferta de material multimodal, elaborada à luz da Sala de Aula Invertida, que propunha ao final, uma situação de uso real da língua. Para culminância dessa tarefa, foi proposta uma aula síncrona, via Google Meet em que os alunos pudessem interagir e também foi oportunizada a possibilidade de gravação de vídeo para aqueles que não pudessem participar.

\section{$O$ advento das TDIC na educação}

Já conhecidas e utilizadas no ensino à distância, após o crescimento exponencial dessa modalidade na educação, as TDIC passaram, durante o contexto pandêmico a fazer parte das nossas vidas acadêmicas de vez. As ferramentas tecnológicas, quando utilizadas de forma crítica e pertinente, possibilitam práticas significativas nos mais variados contextos. Moran; Masetto e Behrens (2017) ampliam a discussão e argumentam que as tecnologias permitem ampliar o conceito de aula, uma vez que estabelecem pontes novas entre o estar juntos e conectados a distância. Através das tecnologias podemos mesclar espaços e tempos possibilitando o melhor aproveitamento dos aprendizes.

O professor, até aqui já multifacetado, passou a se transformar cada vez mais para operacionalizar as mudanças voltadas a um perfil distinto de alunos que já não são mais passíveis apenas do recebimento de informações, mas sim já demandam conhecimentos habilidades típicas de sujeitos da geração $\mathrm{Z}$, cada vez mais conectada.

A aprendizagem pode ser estimulada através do uso das TDIC, visto que os alunos têm um interesse natural pelas tecnologias. Isto pode aproximar os jovens das atividades propostas, resultando em atividades mais significativas. Existem distintos aplicativos e ferramentas voltadas para o uso educacional, mas esta nem sempre a realidade dos alunos e das nossas escolas, sobretudo as públicas. É comum que os alguns jovens não tenham muito domínio tecnológico ligado à educação e por isso, o telefone celular foi a ferramenta mais utilizada. Visto anteriormente como fator de distração e até mesmo proibido em algumas salas de aula o smartphone é o que temos de mais acessível tanto em termos financeiros quanto tecnológicos para uso nas escolas públicas, caso desse relato.

\footnotetext{
Na sala de aula o celular é a tecnologia móvel mais acessível aos alunos, pois com diversidade de marcas e modelos no mercado, seu valor torna-se relativamente acessível, e alguns alunos já o trazem para sala de aula como uma ferramenta de consulta a materiais educacionais ou mesmo para realizar comunicação (BOTTENTUIT JUNIOR, 2019, p.16).
}

As TDIC já ocupam o espaço na vida dos jovens da geração $\mathrm{Z}$, cabe agora, aos profissionais de educação usar essa tecnologia a seu favor, através de planejamentos criativos em que os alunos percebam seu envolvimento e aproveitamento real. Eles devem ser capazes de interagir, pesquisar seu material, descobrir respostas aos questionamentos de forma autônoma e essa autonomia está 
ligada à metodologia usada pelos professores. As possibilidades de exploração e desenvolvimento não devem se esgotar em uma única aplicação

Existem muitos modelos de Metodologias Ativas capazes de promover o engajamento dos alunos para a construção do seu próprio conhecimento. Sobre esse engajamento e a metodologia específica, tratada em nossa pesquisa, falaremos logo a seguir

\section{A autonomia dos alunos através da Sala de Aula Invertida}

A cada novo ano letivo - e até antes dele - os professores são desafiados a repensar suas práticas tornando-as mais atrativas aos educandos, que se mostram menos passivos e mais ativos. Oportunizar novas e significativas experiências é um dos objetivos das Metodologias Ativas, que quando bem organizadas e planejadas permitem que o aluno se sinta livre para buscar novos conhecimentos, mas orientados sobre o que buscam.

As metodologias precisam acompanhar os objetivos pretendidos. Se quisermos que os alunos sejam proativos, precisamos adotar metodologias em que os alunos se envolvam em atividades cada vez mais complexas, em que tenham que tomar decisões e avaliar resultados com apoio de materiais relevantes (MORAN, 2015, p.17).

O planejamento dessas atividades deve levar em conta a proximidade com a vida dos alunos e assim garantir que eles observem sua relevância cotidiana. De nada adiantam aqueles modelos tradicionais em que os jovens apenas reproduzem respostas prontas, que não dialogam com sua realidade.

A escolha da Sala de Aula Invertida como a Metodologia Ativa a ser utilizada se dá pela ampla possibilidade de trabalho em momentos síncronos e assíncronos, usando a possibilidade dessa mescla para enriquecimento das experiências.

Bacich e Moran (2018) argumentam que as Metodologias Ativas propiciam uma aprendizagem mais profunda por possibilitar essa hibridização de tempos e espaços, a flexibilidade dos processos de aprendizagem, que incluem o aprender fazendo, demonstram que o processo de aprender é sempre múltiplo, mesmo em espaços formais. A ênfase na aprendizagem ativa proporciona conhecimentos mais ricos que valorizem também os conhecimentos prévios dos aprendizes.

Os modelos de Metodologias Ativas híbridas como é o caso da Sala de Aula Invertida, contam com a mediação tecnológica, que não é uma obrigatoriedade, porém traz o interesse dos jovens para mais perto do contexto da aprendizagem de aula, o que como já citamos, torna a aprendizagem mais significativa, uma vez que os alunos veem sentido naquilo que propomos que eles desenvolvam.

Pensando sobre educação formal, que conta com o aporte físico da sala de aula, podemos imaginar diversas combinações e/ou dinâmicas possíveis para alcançar os objetivos desejados e desenvolver as habilidades propostas. Invertendo a forma de ensinar, através do uso da Sala de Aula Invertida, proporcionamos maior alcance das habilidades estudantes o que flexibiliza seu aprendizado e aumenta sua autonomia.

A metodologia em questão, denominada SAI, consiste na inversão de atividades, o que tradicionalmente costumava ser feito na sala de aula com a presença do professor passa a ser feito 
em casa de forma assíncrona, enquanto as atividades antes enviadas para casa, fazem parte da interação presencial ou síncrona, considerando o modelo híbrido.

\begin{abstract}
A sala de aula invertida não se organiza em torno de vídeos, mas a maioria das pessoas que invertem a sala de aula usam vídeos como meio de oferecer instruções diretas. A única característica em comum de todas as salas de aula invertidas é a do desejo de redirecionar a atenção na sala de aula, afastando-a do professor e concentrando-a nos aprendizes e na aprendizagem (BERGAMANN; SAMS, 2019, p.89).
\end{abstract}

Para aplicabilidade das Metodologias Ativas, sobretudo a SAI, se faz necessário repensar papéis desenvolvidos dentro do âmbito escolar para que o aprendiz tenha a real noção no seu papel desenvolvimento cognitivo que lhe trará benefícios. Somente receber informações e reproduzi-las já não é mais suficiente para a formação de cidadãos ativos socialmente. É preciso descentralizar a aula da figura do professor que atuará como curador na escolha de materiais que possam ser úteis e de tutor que orientará atividades que demandem maior participação por parte dos alunos.

\title{
Considerações finais
}

Durante nosso trabalho, o objetivo foi repensar o ensino de Libras como L2 para ouvintes neste momento pandêmico através das Metodologias Ativas e apoiado nas TDIC, sobretudo, nos resultados de aprendizagem que os vídeos podem proporcionar, usando como recurso principal e mais abrangente, considerando-se que a Libras é uma língua visual.

O vídeo também proporciona maior imersão do aprendiz na língua pensando no uso dela de maneira cotidiana e real, para que quando em contato com o surdo, os conhecimentos linguísticos possam ser colocados em prática.

O feedback dos alunos em relação as metodologias aplicadas foi positivo, pois os eles relataram que a partir do uso dos vídeos, puderam se auto-observar, logo, perceberam e realizaram modificações nos discursos, no intuito de melhorá-los, o que não seria possível dentro da presencialidade. Por outro lado, sabemos que o acesso às tecnologias, às redes e até mesmo a dependência que alguns alunos podem apresentar, impedem que o resultado trabalho seja completamente positivo. Ainda ficam pontos a serem repensados e melhorados, como por exemplo, o uso de aplicativos - disponibilizados na sequência didática multimodal - que somente funcionam com acesso à internet. Aqueles alunos com dificuldades de conexão ou até mesmo com smartphones menos atualizados, sentiram mais dificuldades na pesquisa de vocabulário e até mesmo execução das suas tarefas finais. Sobre a dependência também citada, é importante que a escola como um todo repense os papéis em seu âmbito, para que o professor descentralize realmente o foco em si, possibilitando a autonomia dos alunos, que aprenderão a andar pelos seus próprios caminhos, através das suas dúvidas e construindo seus conhecimentos.

Como discentes, avaliamos que o uso do vídeo tanto para fazer as explicações, manter diálogo ou produzir novos discursos, além de produtivo, respeita o ritmo de aprendizagem do aluno, pois permite reproduções em maior ou menor velocidade, além de permitir uma prática social da linguagem que pode ser aplicada no dia a dia. 


\section{Referências}

BACICH, L.; MORAN. J. (Org.). Metodologias ativas para uma educação inovadora: uma abordagem téorico-prática. Porto Alegre: Penso, 2018.

BERGMANN, J.; SAMS, A. Sala de aula invertida: Uma metodologia ativa de aprendizagem. Tradução de Afonso Celso da Cunha Serra. Rio de Janeiro: LTC, 2019.

BOTTENTUIT, J. B. Sala de Aula Invertida: Recomendações e Tecnologias Digitais para sua Implementação na Educação. Revista Novas Tecnologias na Educação - RENOTE, v. 17, n. 2, ago. 2019. Disponível em: <https://seer.ufrgs.br/renote/article/view/96583/54183>. Acesso em: 28 fev. 2021.

MORAN, J. M.; MASETTO, M. T.; BEHRENS, M. A. (Ed.). Novas tecnologias e mediação pedagógica. 13. ed. São Paulo: Papirus, 2007.

MORAN, J. M. Mudando a educação com metodologias ativas. In Convergências Midiáticas, Educação e Cidadania: aproximações jovens. Coleção Mídias Contemporâneas, v. 2, 2015. Disponível em: <http://rh.unis.edu.br/wp-content/uploads/sites/67/2016/06/Mudando-a-Educacao-com-Metodologias-Ativas.pdf>. Acesso em: 2 mar. 2021. 